\title{
Florestas Culturais: Memória e Cultura nos processos de Emergência Étnica na Amazônia, Rio Andirá, quilombo Matupiri, Barreinha-AM
}

\section{Cultural Forests: Memory and Culture in processes of Ethnic Emergence in Amazonia, Rio Andirá, quilombo Matupiri, Barreinha-AM}

\author{
DOI: $10.46814 / \operatorname{lajdv3n3-038}$
}

Recebimento dos originais: 01/052021

Aceitação para publicação: 31/06/2021

\section{João Marinho da Rocha}

Professor do colegiado de História da Universidade do Estado do Amazonas, Centro de Estudos Superiores de Parintins-UEA/CESP. Doutor em Sociedade e Cultura na Amazônia pela UFAM. Pesquisador do Grupo de Estudos Históricos do Amazonas-GEHA e do Núcleo de Estudos afrobrasileiros-NEAB,

E-mail: jmrocha.hist@hotmail.com / jmdrocha@uea.edu.br.

\section{RESUMO}

Entender os processos e formas de conhecimentos criadas e acionados pelos sujeitos sociais do rio Andirá, quilombo Matupiri, Barreirinha-AM para a constituição da sua recente Identificação Étnica como quilombolas" é foco deste texto. Dialogamos com as "Questões de Identidade e Hibridismo Cultural" sugeridas a partir das leituras (HALL, 2003), (BURKE,2003) e estudos como (FUNES,1995), (GOMES,1997), (SAMPAIO,2011), quem indicam o fim do silêncio para a presença negra na configuração histórica e social da Amazônia, onde inúmeras emergências Étnicas por toda região nos últimos vinte anos. Identificar, descrever e refletir tais emergências é um dos objetivos deste texto que é um fragmento inicial da proposta de Tese junto ao Programa de Pós-Graduação em Sociedade e Cultura na Amazônia PPGSCA/UFAM. Boa Fé, Ituquara, São Pedro, Santa Tereza do Matupiri e Trindade constituem o Matupiri que, após dez anos de lutas locais e regionais articulados aos demais contextos e "agentes externos", foi reconhecido como remanescente de quilombolas pela Fundação Cultural Palmares (Portaria No 176, de 24 de outubro de 2013). Nos ocupamos da compreensão desses processos de Identificação Étnica como remanescente no Rio Andirá, tradicionalmente associado como território do povo indígena Sateré-Mawé. Os sujeitos sociais do Matupiri acionaram inúmeros mecanismos para compor seu processo de constituição Identitária como remanescentes quilombolas. As festas populares aparecem como espaços simbólicos de pertencimento, onde são atualizadas as memórias do cativeiro e dos mundos vividos naquela fricção Étnica do rio Andirá que apontam para as "florestas culturais" existentes nas Amazônias. Enquanto "sujeito de direito" (MATTOS,2006), os negros do rio Andirá passaram a acionar uma memória do cativeiro que deu sustentação para sua luta por reconhecimento como comunidades remanescentes quilombolas. A memória passou então a desempenhar importante papel na construção de caminhos que os levassem ao “dizer-se e ser" (BRANDÃO, et all,2010) quilombola no Andirá. As primeiras estratégias foram marcadas pelo levantamento das reminiscências dos idosos, que passaram a ser os guardiões da memória, implicando-lhes novos valores às histórias contadas por seus pais e avós, (MATTOS,2006). Tais valores foram revestidos com a força da tradição oral os ligou a um passado da escravidão negra na Amazônia, legitimando sua luta pela titulação de suas "terras tradicionalmente ocupadas" (ALMEIDA,2008). A memória serviu no Matupiri como suporte para organizar as manifestações folclóricas que passam a ser "ritualizadas" nas comunidades em datas específicas e com isso constituem os "processos de vivências de uma memória coletiva" (ORTIZ,2006) sobre aquele grupo que se liga a experiência da escravidão do século XIX, e que, a partir de sua realidade social deste contexto do início do século XXI, busca acessar seus direitos coletivos enquanto grupo Étnico diferenciado no rio Andirá. 
Palavras-chave: Memória, Cultura, Emergência Étnica, Quilombos do rio Andirá.

\begin{abstract}
The focus of this text is to understand the processes and forms of knowledge created and used by the social subjects of the Andirá River, Matupiri quilombo, Barreirinha-AM, for the constitution of their recent Ethnic Identification as quilombolas. We dialogued with the "Identity Issues and Cultural Hybridity" suggested from readings (HALL, 2003), (BURKE, 2003) and studies such as (FUNES, 1995), (GOMES, 1997), (SAMPAIO, 2011), which indicate the end of silence for the black presence in the historical and social configuration of the Amazon, where numerous Ethnic emergences throughout the region in the last twenty years. Identifying, describing and reflecting on such emergences is one of the objectives of this text, which is an initial fragment of the Thesis proposal to the Graduate Program in Society and Culture in the Amazon PPGSCA/UFAM. Boa Fé, Ituquara, São Pedro, Santa Tereza do Matupiri and Trindade constitute Matupiri that, after ten years of local and regional struggles articulated with other contexts and "external agents", was recognized as remaining quilombolas by the Palmares Cultural Foundation (Ordinance No. 176, October 24, 2013). We are concerned with understanding these processes of Ethnic Identification as a remnant in the Andirá River, traditionally associated as territory of the indigenous Sateré-Mawé people. The social subjects of Matupiri triggered numerous mechanisms to compose their process of Identity constitution as quilombola remnants. The popular festivals appear as symbolic spaces of belonging, where the memories of the captivity and of the worlds lived in that Ethnic friction of the Andirá River are updated, pointing to the "cultural forests" that exist in the Amazons. As "subjects of law" (MATTOS, 2006), the black people of the Andirá River began to activate a memory of captivity that provided support for their struggle for recognition as remaining quilombola communities. The memory then began to play an important role in the construction of paths that would lead them to "say and be" (BRANDÃO, et all, 2010) quilombola in Andirá. The first strategies were marked by the collection of reminiscences of the elderly, who became the guardians of memory, implying new values to the stories told by their parents and grandparents (MATTOS, 2006). Such values were coated with the strength of oral tradition linking them to a past of black slavery in the Amazon, legitimizing their struggle for the titling of their "traditionally occupied lands" (ALMEIDA,2008). The memory served in Matupiri as a support to organize the folkloric manifestations that become "ritualized" in the communities on specific dates and thus constitute the "processes of experiences of a collective memory" (ORTIZ, 2006) about that group that is linked to the experience of slavery in the nineteenth century, and that, from its social reality of this context of the early twenty-first century, seeks access to their collective rights as a differentiated Ethnic group in the Andirá River.
\end{abstract}

Keywords: Memory, Culture, Ethnic Emergence, Quilombos of the Andirá River.

\title{
1 INTRODUÇÃO
}

Com a indagação de como os pressupostos trazidos por alguns autores dos chamados estudos culturais podem auxiliar nos entendimentos das culturas humanas é que intencionamos aqui estabelecer um diálogo entre os processos e formas de conhecimentos acionados pelos sujeitos sociais do rio Andirá, quilombo Matupiri para a constituição da sua "Nova Identidade quilombola" na Amazônia e as "Questões de Identidade e Hibridismo Cultural" sugeridas a parir das leituras (HALL, 2003), (BURKE, 2003). 
As comunidades do rio Andirá, quilombo Matupiri, Barreirinha-AM, lutaram por cerca de dez anos por titulação, receberam o título como remanescentes em 2013 (Portaria No 176, de 24 de outubro de 2013 registrou no Livro de Cadastro Geral n ${ }^{\circ}$ 16). No entanto, ainda buscam legitimarem-se cada vez mais como grupo Étnico. Daí as festas tornam-se espaços privilegiados de afirmações identitárias na medida em que buscam elementos que os liguem ao passado comum que é a experiência da escravidão na Amazônia experimentada por seus antepassados.

Este texto se apresenta como um esforço inicial do processo de compreensão de como que os sujeitos do quilombo Matupiri, vem se mostrando enquanto novo grupo Étnico no rio Andirá, ou seja, como constroem sua Identidade e acionam a busca por direitos perante os órgãos constituídos? Ou seja, entender iluminar sobre como à luz de contextos nacionais de emergência das "novas Identidades quilombolas" (MATTOS, 2006), os sujeitos sociais do Matupiri acionaram inúmeros mecanismos como os elementos da cultura, por meio da reorganização de algumas festas populares, para compor seu processo de constituição Identitária como remanescente.

Estamos atentos nesse percurso reflexivo para os papeis desempenhados pela memória oral nos processos de constituição da Identidade Étnico-racial quilombola no rio Andirá, quilombo Matupiri. A partir de um despertar para sua condição enquanto "sujeito de direito" (MATTOS, 2006), os negros do Andirá passaram a acionar uma memória do cativeiro que deu sustentação para sua luta por reconhecimento como comunidades remanescentes quilombolas.

A memória passou então a desempenhar importante papel na construção de caminhos que os levassem ao “dizer-se e ser” (BRANDÃO, et all, 2010) quilombola no Andirá. As primeiras estratégias foram marcadas pelo levantamento das reminiscências dos velhos e velhas das cinco comunidades (São Pedro, Trindade, Boa Fé, Ituquara e Santa Tereza) que passaram a ser os guardiões da memória, implicando-lhes novos valores às histórias contadas por seus pais e avós, (MATTOS, 2006).

Tais valores foram revestidos com a força da tradição oral os ligou a um passado da escravidão negra na Amazônia, legitimando sua luta titulação de suas "terras tradicionalmente ocupadas" (ALMEIDA, 2008).

Essa memória do cativeiro passou então a servir de base para (re)constituição de modos de ser e viver naquele território, mas especialmente, auxiliou no processo de (re)organização da vida cultural das comunidades que passaram a legitimar a feitura de festas populares com a presença de inúmeras danças como gambá e onça te pega, pássaros como jaçanã e garcinha, dar outros sentidos as festas de santo da comunidade, assim como na reestruturação da festa de boi-bumbá que passou a se relacionar cada vez mais com outros espaços culturas da região.

Ao que tudo indica, a memória serviu no Matupiri como suporte para organizar as manifestações folclóricas que passam a ser "ritualizadas" nas comunidades em datas específicas e com 
isso constituem os "processos de vivências de uma memória coletiva" (ORTIZ, 2006) sobre aquele grupo que se liga a experiência da escravidão do século XIX, e que, a partir de sua realidade social deste contexto do início do século XXI, busca acessar seus direitos coletivos enquanto grupo étnico diferenciado no rio Andirá.

Os registros e as análises das narrativas orais dos sujeitos do quilombo, pautadas na metodologia da História Oral (MEIHY, 2005), (MEIHY e HOLANDA, 2011), indicam que, ao lado de outros processos e formas de conhecimentos, as inúmeras festas populares, realizadas são pensadas como espaços de sociabilidades, que auxiliam na pertença a determinados espaços físicos, sociais e culturais e, portanto, indicam elementos que compõe a nova Identidade Étnico-racial no Andirá, quilombo Matupiri.

\title{
2 CENÁRIOS DE DIREITOS, LUTAS POR RECONHECIMENTO E EMERGÊNCIAS DE NOVAS IDENTIDADE ÉTNICO-RACIAIS NO BRASIL.
}

Nas duas últimas décadas do século XX como fruto das pressões dos grupos sociais e demais órgãos e instituições forjadas no bojo da transição do regime civil-militar para o democrático, o Brasil assistiu, a um cenário que possibilitou a criação de dispositivos legais materializados na constituição de 1988, por meio de seu artigo 68. Isto fez com que populações as chamadas tradicionais como os remanescentes de quilombos pudessem articular vários mecanismos para o reconhecimento de suas identidades coletivas e territórios. Brandão et all, (2010, p.77), destacam que

\begin{abstract}
as discussões públicas e as ações políticas ancoradas em perspectivas tipicamente multiculturais têm invadido a cena pública brasileira nas últimas décadas. Neste campo as questões relacionadas ás relações raciais e os problemas advindos das desigualdades entre os grupos de cor e raça se destacam. Exemplos disto: a) na Carta Constitucional de 1988, que reconheceu a propriedade da terra às comunidade quilombolas, b)na adoção de cotas raciais por inúmeras universidades públicas brasileiras a partir de 2004 (...), c) na promulgação da lei $\mathrm{n}^{\circ} 10.639 / 2003$ que estabelece o ensino de história e cultura afro-brasileira na educação fundamental, e, d) na políticas públicas voltadas especificamente para os quilombolas, tal como as que se encontram em execução no programa Brasil Quilombola (iniciado em 2004).
\end{abstract}

Nesse contexto, onde muitas comunidades negras rurais da Amazônia, como é o caso do município de Oriximiná - PA, onde,

As comunidades remanescentes de quilombos têm realizado, por meio da Associação dos Remanescentes de Quilombo do Município de Oriximiná-ARQUIMO, a titulação coletiva das áreas que ocupam que segue a prática do uso comum do território para atividades extrativas e produção familiar de subsistência (O’DWEYER, 2005, p. 8).

Para essa autora a categoria quilombola foi encorajada pela situação social presente de conflitos com as mineradoras que como a mineração rio do norte que associada interesses nacionais, regionais e 
locais, avança para seus territórios tradicionalmente ocupados. Essa situação de conflito, para O’Dwyer possibilitou os Negros de Boa Vista a emergirem enquanto "Identidade étnica".

Em seu texto "Reinventando a história dos quilombos: rasurando e confabulando", Price, (1999) ao realizar um levantamento dessas emergências da comunidade remanescente no Brasil num paralelo com as comunidades de outros países da América do Sul e Central, aponta também o pioneirismo das comunidades negras rurais do Baixo Amazonas nesse processo de Etnogênese, onde,

Em 1989, (...) se organizaram como Associação das Comunidades Remanescentes de Quilombo do Município de Oriximiná e, com a ajuda de antropólogos e outros peritos designados, começaram a militar pela posse da terra. Em novembro de 1995, a comunidade de Boa Vista se tornou a primeira em todo o Brasil a receber o título de posse coletiva da terra, com base no Art.68 da constituição. (...). Em novembro de 1996, duas comunidades vizinhas, Água Fria e Pacoval (...), se tornaram a segunda e a terceira no país a receber suas terras, de acordo com o Art. 68”. Price, (1999, p.18).

Nessa luta por reconhecimentos como comunidades de remanescentes de quilombo, tais comunidades de todo Brasil, se articulam para acessar seus direitos, indicados no âmbito da ressignificação do termo quilombo, do artigo 68 do Ato das Disposições Constitucionais Transitórias (ADTC) da constituição federal de 1988. Tal artigo confere direitos territoriais aos remanescentes de quilombo que estejam ocupando suas terras, sendo-lhes garantida a titulação definitiva pelo Estado brasileiro (O’DWEYER, 2005). “Ali se nomeava e se atribuía direitos a um heterogêneo conjunto de comunidades de predominância negra que, salvo raras exceções, não se pensavam em qualquer medida como 'remanescentes das comunidades de quilombos' (BRANDÃO et all,2010, p.78) ". Sua aprovação proporcionou uma "revisão histórica e mobilização política, que conjugava a afirmação de uma identidade negra no Brasil à difusão de uma memória da luta dos escravos contra a escravidão" (MATTOS, 2005).

É também nesse contexto que o termo quilombo deixa suas limitações históricas, a partir do modelo de palmares, forjado no contexto da colonização, onde o conselho ultramarino definiu quilombo como "toda habitação de negros fugidos, que passassem de cinco, em parte despovoada, ainda que não tenha ranchos levantados e nem se achem pilões nele". Esta definição influenciou toda uma pesquisa histórica da temática quilombola até a década de 1970 (SCHIMITT, et all,2002).

Dentro desse cenário de possibilidades e dispositivos legais, é que serão encampadas lutas por todo país por reconhecimento das terras de remanescentes de quilombo. Somam-se a isso, outras questões, pois, “além da referência Étnica e da posse coletiva da terra, também os conflitos fundiários vivenciados no tempo presente aproximavam o conjunto das 'terras de preto', habilitando-as a reivindicar enquadrar-se no novo dispositivo legal" (MATTOS, 2005, p.106). 
Ao se referir a esses novos grupos étnicos, que tradicionalmente ocuparam suas terras, Almeida, (1998, p.17), afirma que

A situações históricas peculiares em que grupos sociais e povos percebem que há condições de possibilidade para encaminhar suas reivindicações básicas, para reconhecer suas identidades coletivas e mobilizar forças em torno delas e ainda para tornar seus saberes práticos um vigoroso instrumento jurídico-formal.

Esse contexto reivindicado socialmente abriu, portanto, possibilidades para a busca dos direitos diferenciados de grupos étnicos-raciais que foram criados na forja da história colonial, marginalizados e esquecidos na construção da nação e ressurgidos no contexto multiculturalista do final do século 20. Apresentando-se enorme desafio para historiadores, Antropólogos e Cientistas Sociais engajados entorno da questão. (MONTEIRO, In: ARRUTI, 2006).

Nesse cenário de possibilidades de busca por acessar direitos e (re) afirmação Identitária no Brasil, vale ressaltar a atuação dos movimentos sociais, com destaque para os movimentos negros que

Buscam formas concretas de expressões culturais para interpretá-las dentro de uma perspectiva mais ampla. (...). Ao integrar em um todo coerente as peças fragmentadas da história da África (negra) - candomblé, quilombos, capoeira- os intelectuais constroem uma identidade negra que unifica os atores que se encontravam anteriormente separados. A identidade é neste sentido elemento de unificação das partes, assim como fundamento para uma ação política (...) (ORTIZ, 2006, P 141)

Esse contexto proporciona uma transição de uma homogeneidade cultural para o reconhecimento de Identidade Étnico-raciais. Sobre essa questão, Costa afirma lembra que

A identidade Nacional foi sustentada em três pontos fundamentais: a democracia racial, a brasilidade e a homogeneidade cultural. Pontos ainda presentes e fortemente marcados no imaginário social. (...) historicamente a identidade nacional passou a ser representada a partir de novos processos de reetinização das identidades políticas. Contemporaneamente, essas vêm contrapondo-se à mestiçagem enquanto ideologia do Estado, fazendo com que a Pluralidade Cultural seja vista como afirmação das diversas identidades que formam a nação brasileira. Essas ideias remetem a mudanças, no que se refere à constituição de uma identidade nacional, a qual, agora, está longe de ser aquela que tinha um caráter uniformizador onde as diversas culturas eram sufocadas em favor de uma identidade homogeneizadora. (CONSTA, 2011, p.52)

Sobre esse contexto de reconhecimento das Identidades, construído socialmente nas duas últimas décadas do século XX no país, Almeida enumera alguns sociais que se mobilizavam entorno da causa do reconhecimento de seu território,

No início da década de 90 foram às chamadas "quebradeiras de coco babaçu" e os "quilombolas" que se colocaram na cena política constituída, consolidaram seus movimentos e articularam estratégias de defesa de seus territórios, juntamente com outros povos e comunidades tradicionais, tais como os "castanheiros" e os "ribeirinhos" (...). Além destes começaram a se consolidar no último lustro, as denominadas "comunidades de fundos 
de pasto" e dos "faxinais". Estes movimentos, tomados em seu conjunto, reivindicam o reconhecimento jurídico-formal de suas formas tradicionais de ocupação e uso dos recursos naturais. (ALMEIDA,1998, p.19).

As comunidades passam a se articular entorno de elementos que os unisse na busca de acessar seus direitos. Para isso acionam os mais variados elementos e entidades externas. Essa questão legal se consolidou quando o decreto 4.887, de 20/11/2003 regulamentou que a caracterização dos remanescentes das comunidades dos quilombos será atestada mediante auto identificação da própria comunidade".

Tais comunidade, por sua vez, passam a ser compreendidas também como "grupos étnicosraciais, segundo critérios de auto atribuição, com trajetória histórica própria, dotados de relações territoriais específicas, com presunção de ancestralidade negra relacionada com a resistência à opressão histórica sofrida".

Nos primeiros anos de década passada, as comunidades negras rurais do Matupiri, em diálogo intenso com as experiências das outras partes do país, especialmente do Oeste Paraense dão início ao seu processo de luta por reconhecimento enquanto remanescentes que possuem territorialidades específicas no rio Andirá.

\section{MEMÓRIA E CULTURA NOS PROCESSOS DE EMERGÊNCIA ÉTNICA NO RIO ANDIRÁ, QUILOMBO MATUPIRI.}

As festas populares realizadas no quilombo Matupiri, especialmente a parir do contexto de luta por reconhecimento como remanescentes quilombolas, (re) aparecem baseadas nas narrativas orais dos mais velhos daquelas comunidades. Essas festas indicam inúmeras possibilidades de construção de uma memória que acusa processos identidade ou melhor, dos "processos de identificação" como aponta (HALL,2003).

Nossas pesquisas realizadas no Matupiri a partir de 2013, têm apontado para uma crescente participação dessas manifestações da cultura popular no processo de constituição da Identidade Étnica. Essa memória entorno das origens tem recebido relevo a cada ano.

Tal fato fica evidente por exemplo nos processos de sistematização dessas festas ao longo do ano, na preocupação em sua preparação, na atenção em envolver o maior e variado número possível de sujeitos das comunidades que compõem o quilombo e das comunidades próximas.

Chamamos especial atenção para o enfoque dado a participação crescente de Crianças nessas festas. Destacamos isso principalmente na festa do boi-bumbá "trinca terra", onde a cada ano surgem novas "tribos infantis" como itens desse festival, nas quais as crianças são pintadas com motivos afrobrasileiras, mas também representam algo relacionado ao ambiente e culturas locais do Andirá. 
Destacamos ainda nesse processo de utilização da cultura no percurso de constituição da Identidade Étnico-racial no Andirá, quilombo matupiri, os diálogos intensos entre as culturas regionais e o ser quilombola. Um forte indicativo disso foi separação a festa do boi-bumbá das demais danças tidas por eles, como tradicionais, a exemplo da "onça te pega" e "gamba", dos pássaros "jaçanã" e "garcinha" devidamente exploradas na sequencia desta reflexão.

Tal escolha de separação parece não se dá num acaso, mas insere-se num contexto onde a "cultura dos festivais folclóricos" vem crescendo no Estado do Amazonas nas últimas duas décadas, sendo na maioria dos casos o "carro-chefe" nas políticas culturais oficiais do governo, principalmente quando se trata do interior do Estado, (NOGUEIRA, 2000).

No Estado do Amazonas nas principais cidades que formam as sub-regiões, onde não tenha um "festival folclórico" em que se exalte as culturas locais ou processos de vida e trabalho "dos homens e mulheres da floresta".

A manifestação de destaque nesses festivais é o boi-bumbá em primeiro plano, havendo eventuais aberturas para outras manifestações como pássaros, cordões de danças típicas locais associados a algum elemento da fauna (onça branca e pintada - Tabatinga-AM; cardinal e cará disco em Barcelos-AM) da flora ou representação do trabalho das comunidades.

Então, o que se vê são as redes de relações dessa "cultura de festivais" adotada pelo governo para o interior do Estado e as maneiras como os povos e comunidades tradicionais, a exemplo dos remanescentes de quilombo do Matupiri, também se apropriam desse contexto para dar mais sentido e visibilidade regional e até nacional para sua luta por reconhecimento Étnico. Nesse movimento, as danças acabam trazendo para si lugares e espaços de pertencimento que dizem sobre as culturas locais e afirmam em certa medida processos de identificação de muitos grupos humanos vivem/sobrevivem e que são a Amazônia. Uma região se que efetiva numa relação constante, desigual e histórica entre o local, o regional e o global.

Essas relações se visualizam nos processos de emergências étnicas locais. É marcada a presença de agentes externos nos movimentos de construção da Identidade local. Nas festas isso se visualiza quando as comunidades quilombolas do Matupiri constroem múltiplas redes de relações com outros espaços, o que possibilita acesso aquela lógica dos festivais tão massificada no estado. A relação se materialização por exemplo nas ajudas externas para o processo de construção do seu festival folclórico de boi bumba.

São evidentes as influências do festival folclórico de Parintins (bois garantido e caprichoso), que passou ser o centro irradiador dessa política dos festivais folclóricos no Amazonas, também se verifica a influência do festival folclórico de Barreirinha (touros branco e touro negro) que cedem muito dos seus adereços e fantasias. Também se percebe essas trocas sobretudo das estruturas de 
pessoal para auxiliar os "artistas do quilombo", que na realidade são os próprios professores, pescadores, agricultores e demais grupos locais que se articulam entorno da festa do boi "trinca terra" e com ela se integram de certo modo a cultura dos festivais tão propagada como identidade cultural no Estado.

Ao fazer essa movimentação para compor seu processo de emergência étnica neste início do século XXI, Matupiri também está movimentando, talvez sem perceber, uma memória que remete ao século XIX. Estamos nos referindo a cultura do bumba- meu-boi que chega à Amazônia junto homens e mulheres nordestinos que trabalharam nos seringais amazônicos e aqui se transforma em boi-bumbá. Após desfazimento dos negócios da economia do látex tais sujeitos tecem outras relações que aos poucos comporão as florestas culturais existentes hoje na Amazônia. A cultura festiva do boi-bumbá que se firmou nuns diálogos com as culturas locais índias e a cultura cristãs católicas fortemente presente na configuração dos espaços simbólicos dos povos e comunidades tradicionais da Amazônia, faz parte da memória histórica que as comunidades negras rurais passam a (re) construir e acessar neste contexto de construção de sua emergência Étnica enquanto sujeitos de direitos.

No Matupiri, o momento das festas, com destaque para o festival folclórico que hora trazemos, aparece desse modo como um espaço de possibilidades para se mostrar tanto às comunidades próximas que participam intensamente, mas sobretudo para o poder público municipal que materializa, ao menos para aquele momento, sua presença naquele distrito por meio de seus secretários e autoridades constituídas.

Os espaços vivências da memória coletiva quilombola, via manifestações da cultura popular parecem ser utilizados no Matupiri, dentre outras coisas, para construir, mobilizar e atualizar a memória do cativeiro criada por eles para indicar identidade Étnica do grupo e promoção de diálogos com demais espaços para afirmar e endossar a busca de diretos coletivos para além da titulação e posse de suas terras tradicionalmente ocupadas, mas para a manutenção e sobrevivência de suas culturas, através das inúmeras práticas sociais e modos de vida. Enfim, para a Emergência de um povo que historicamente marginalizado e que agora emerge no rio Andirá utilizando-se dentre outros processos e formas de conhecimentos os processos culturais.

Nesse cenário da constituição da Identidade no Andirá, dialogamos com as questões trazidas por Hall, (2003), no que tange às suas considerações sobre os processos de mudanças descritos atualmente como "globalização" e suas influencias nos processos de pensar os sujeitos e suas Identidades.

Hall (2003) indica em seu texto que há uma crise das identidades culturais na pósmodernidade, muito da qual provocada pelos processos das mudanças (aceleradas, contínuas e permanentes) trazidas pelo fenômeno da globalização. Isto provoca segundo Hall inúmeros 
"descontinuidades", "fragmentação", "rupturas" e "deslocamento ou descentração", interior das Identidades culturais nacionais e isto focaliza para a importância das Identidades locais e regionais, marcadas pelo hibridismo, o que significaria dizer dentre outras coisas que as Identidades culturais são movidas por mudanças, encontros e desencontros. Esse raciocínio leva o autor a afirmar ao invés de Identidade, seria mais sensato dizer que temos uma Identificação, dada a mudança e pela transformação a que está sujeita, ou seja, toda Identidade é móvel e redireciona-se, portando definida em processos históricos e não biologicamente.

Tal fenômeno parece ocorrer como dezenas de comunidades negras rurais da Amazônia, que a partir das duas últimas décadas do século passado, passaram a acionar Novas Identidades Étnicas, agora afirmando-se quilombolas e tornando-se sujeitos de direito. A Identificação como quilombola na região saiu do campo do silenciamento e "tornou-se politizada" (HALL,2003).

Nesse contexto de entendimentos acerca da Identidade a categoria quilombola no Brasil pode também ser inserida como um exemplo do que discute Hall, na medida em que passou por um processo de ressignificação, distanciando do conceito histórico pautado no modelo palmarino da fuga, quantidade numérica, isolamento social e cultural.

Especialmente na Amazônia, tais comunidade formadas a parir do século XIX são marcadas pela hibridização, configurando-se em comunidades Inter Étnicas compostas de negros fugidos e libertos, indígenas, e demais sujeitos sociais que se conjugavam e articulavam suas vidas para além dos interesses do Estado. Construindo nas cabeceiras dos muitos rios, a exemplo do Andirá espaços de liberdades e identidades que lhes permitiram alcançar o século XXI e agora auto afirmar-se para acessar os direitos de continuarem a viver em suas terras e a garantir manutenção de suas culturas.

Para entender a Identidade, ou melhor, os processos de identificação desse "novo grupo étnico" no Andirá é que se faz necessário a percepção dos inúmeros processos identitários que vem construindo nos últimos anos para afirmar-se quilombolas.

(Guerreiro \& Rocha, 2014) identificaram e descreveram algumas festas populares do quilombo Matupiri, segundo os sujeitos locais. Tal estudo sistematizou as festas em três modalidades básicas, a saber: as danças, com destaque para o lundum, a onça te pega e a do gambá; os pássaros, com destaque para a garcinha e o Jaçanã; as festas de santos católicos, caracterizadas por São Sebastião, Divino Espirito Santo e Santa Tereza e, por fim, a festa de boi-bumbá, a partir do boi-bumbá "trinca terra".

Dada as limitações, neste texto destacamos uma das danças assumida no Matupiri como tradicional que é o gambá, por ser uma festa presente em quase todo Baixo Amazonas, especialmente ali no rio Andirá, sendo também realizado pelo povo indígena Sateré-Mawé, como demais comunidade e grupos folclóricos como na cidade de Maués-AM. Portanto, o gambá pode ser olhado como um representante daquilo que Burke, (2003) chama a "circularidade cultural". 
É importante perceber como que essa festa congrega não apenas entorno do lazer comunitário, mas no Matupiri, associa-se ao mundo do trabalho e das relações trocas de solidariedades entre as populações negras e demais sujeitos daquele rio a exemplo do povo indígena Sateré-Mawé, junto dos quais construíram sociabilidades, Identidades e territorialidades para além do "tenebroso" rio Andirá, nas cabeceiras do Matupiri.

Nesse sentido, a cultura popular, por meio das festas, materializa a afirmação de uma memória do cativeiro e consequente influencia no processo de constituição da Identidade Étnica dos novos quilombolas do Matupiri, onde "existe diversas danças, nós temos boi, festa de santos e temos a nossa tradição de dança: gambá, onça te pega, temos lundum, a garcinha, jaçanã. Todas essas danças são da comunidade remanescente, temos a capoeira”. (Maria Amélia dos Santos Castro, 53anos).

$\mathrm{Na}$ Amazônia, a memória do cativeiro está mais viva entre os velhos, netos e bisnetos de mocambeiros, guardiões das histórias que seus antepassados lhes contavam. (FURNES, In: REIS e GOMES, (1996). Esses sujeitos são depositários de uma memória que, mesmo narrada de forma individual, expressa lembranças coletivas, pois,

Se fizesse um puxirum, um roçado grande. Assim faziam, tanto se a gente fosse convidado como não, era muito animando, era muita gente. Quando davam umas $9 \mathrm{~h}, 10 \mathrm{~h}$ terminavam de plantação, quando terminavam o puxirum era festa. Pegavam o Gambá e pegavam de dança o dia inteiro. Eu me lembro até hoje, era dia inteiro de dança!". (Rafael Cidade de Castro, 54 anos morador da comunidade).

A dança do gambá, efetivada, a partir do batuque de um tambor de mesmo nome, e que está inserida num contexto de realidade vivida na comunidade, a exemplo para celebrar o fim de um trabalho coletivo, conhecido como puxirum, o mutirão amazônico, caracterizado pelas relações de solidariedade e ajuda mútua nas atividades de lavro da terra, em especial no cultivo agrícola.

Quando se realiza o puxirum hoje, se está buscando alguma relação com um passado comum, haja vista que essa prática passa por processos drásticos de transformações, chegando mesmo a desaparecer em muitas partes da região Amazônica. Uma realidade que se aplica ao Matupiri, onde as fazendas dos arredores inserem relações de trabalho baseada no pagamento de diárias. "A memória coletiva é da origem, da vivência, (...), e se manifesta, portanto ritualmente. (...) é encarnada pelo grupo. (...). (ORTIZ, 2006, p.p 35-36). Assim, (re) organizar a dança do gamba parece também significar remeter-se comunitariamente à reorganização de práticas sociais e relações de trabalhos que marcaram o passado dos pais e avós.

As festas que eles faziam aqui na comunidade sempre é festa tradicional mesmo, regional né..., davam alimentação para o pessoal, era café, tinha dança do gambá, que era uma dança da 
cultura deles...essa é uma dança que eles sempre festejavam aqui na comunidade...até agora nós estamos tentando resgatar isso aí na comunidade. (Sidnei Trindade de Castro, 45 anos).

As festas e danças possibilitam a inclusão e elementos culturais de seus ancestrais. Ao narrarem suas lembranças, os remanescentes evocam o passado, como se quisessem transportá-lo para o presente. E neste presente acabam dando outros sentidos e significados às narrativas de seus pais e avós e com isso, as transformam naquilo que Mattos, (2006) chama de "capital cultural simbólico" que serve no processo de constituição da nova Identidade Étnica quilombola.

Como guardiões, esses são os semeadores da cultura local e grande responsáveis pela reconstrução da identidade étnica dos remanescentes. Assim, a memória dos velhos pode ser trabalhada como um mediador entre a nossa geração e as testemunhas do passado. Ela é o intermediário informal da cultura, visto que existem mediadores formalizados constituídos pelas instituições e que existe a transmissão de valores de conteúdos, de atitudes enfim, os constituintes da cultura. Bosi (2003, p.15).

Tais memórias apontam para o desejo de se eternizar e vem essa possibilidade nas festas. Estas, a cada ano envolvem os mais novos nas danças como que apontando para a necessária perpetuação da ancestralidade que liga o matupiri a escravidão negra e pertencimento requerido como remanescentes quilombolas no Matupiri. Tais intenções fazem sentido na medida em que adquirem novos significados que passam a compor, via manifestações da cultura popular, a Identidade Étnica quilombola, pois,

\footnotetext{
"À memória coletiva deve necessariamente estar vinculada a um grupo social determinado. É o grupo que celebra sua vinculação, e o mecanismo de conservação do grupo está estritamente associado à preservação da memória. (...). A dispersão dos atores tem consequências drásticas e culmina no esquecimento das expressões culturais. Por outro lado, a memória coletiva só pode se manifestar no cotidiano das pessoas. (...) as representações só adquirem significado quando encarnadas no cotidiano dos atores sociais. (ORTIZ, 2006, p.133)
}

Além das festas como espaços de vivencias e atualização da memória, há outras práticas também associadas a essas festas e ao mundo do trabalho, das relações de solidariedade, que requerem a ancestralidade no Matupiri. Pontuadas na memória coletiva da escravidão negra na Amazônia, elegem práticas cotidianas que os ligam aos seus antepassados que para certas ocasiões "faziam biscoito, o pessoal que vinham e eles faziam aquela mesada de comida era café com biscoito. Faziam aquela mesa grande, chamavam aquele povo para comer, só para comer mesmo, davam e não cobravam nada, me lembro até hoje". (Rafael Cidade de Castro, 54 anos). Tais práticas continuam no Matupiri

A gente ainda usa essa moda dos antigos né, a gente não deixa de usar por que eles deixaram de lembranças para a gente, as festas que a gente fazia, que a gente faz ainda. Agora em outubro nós festejamos é a padroeira daqui desse novo distrito. Então nós temos acostumado ainda compra os bois para dá povo né, tu faz o café que a gente ainda do povo. (...) Esse foi o costume dos velhos que eles faziam né, a gente usa aquele gambá que era festa de antigamente. 
O gambá é um tambor(...), gambá é um pau grosso assim (gestos) que tem um buraco por dentro, põem o coro de uma caça (...). Eles tiram o coro da caça, eles espicham na cara daquele pau, aquilo ele bati assim (gestos).

Fica tipo um tambor, só que é comprido, uma braça assim no chão, eles sentam em cima, bate com a mão.

É um pedaço de pau que tem buraco por dentro, chamo gambá pra ele, apelido dele, que o nosso avô deixaram pra nós gambá, né o pessoal ainda usa, é esse tipo de dança é...as brincadeira que usam aqui. Quem participava do gambá é os velharada (...) a maioria dos velhos já morreram. Estão tem pouca gente desse antigos, e tinha um da caixinha, outro do gambá, os retos cantava, tipo uma banda, eles cantavam as cantigas, primeiro um depois outros faz a segunda.

Tinha umas flautinha de bambu assim eles tocavam, eles tocavam também. Agora essa daqui por que já mudou é mais com a turma da banda de Parintins, de Barreirinha pra fazer essas feitas né, tirando essa dali é mais com gambá que ele chama, então eles se reuni dessa turma pega até o chapeleiro (comunidades vizinha ao quilombo), então esses mais velhos ainda se lembram dessas cantigas, eles venham se reuni aqui os mais velhos da turma né, ainda cantam ai.

E agora quem participa é o jovem já tem vários jovens já de idade que participa dessa brincadeira, das outras diversão também tinham o boi, a onça te pega e a aquela... tem uma brincadeira que se chama jaçanã pra ele, e a outra é garcinha também é outra brincadeira que tem. (Antônio Belém da Silva, 61 anos).

(...) eles botavam o gambá na ...lá no barracão né e batiam o gambá e dançavam como eles dançam pra lá pro...lá pro lados índios é assim também né, dançando o gambá (...). Quem era de menor não dançavam, só dançava gente graúda mesmo, então só para comer e dormir naqueles tempos e hoje não, ainda amanhece criança por ali dançando né, naquele tempo não (Maria Benedita Ribeiro de Castro, 68 anos).

Essas e outras narrativas auxiliam na compreensão das dinâmicas das festas populares no Matupiri, suas relações com outros elementos culturais das demais composições étnicas daquele rio, mas especialmente, apontam para Memórias coletivas servem para os processos de constituição identidades coletivas como remanescentes de quilombo. Isto se considerarmos que

Enquanto representação social, a identidade é uma construção simbólica de sentido, que organiza um sistema compreensivo a partir da ideia de pertencimento. A identidade é uma construção imaginária que produz a coesão social, permitindo a identificação da parte com o todo, do indivíduo frente a uma coletividade, e estabelece a diferença. A identidade é relacional, pois ela se constitui a partir da identificação de uma alteridade. (PESSAVENTO, 2014, p.p.89 -90).

A memória popular ou as memórias populares tendem, portanto, a se transformar em vivências, pois somente desta forma fica assegurada a sua permanência através daquilo que Ortiz, (2006) chama de das representações teatrais que se politizam em função dos interesses atuais dos sujeitos do quilombo. Para estes sujeitos a identidade se apresenta "como um capital simbólico de valoração positiva, que deve atrair a adesão, ir ao encontro das necessidades mais intrínsecas do ser humano de adaptar-se e ser reconhecido socialmente" (PESSAVENTO, 2014, p.91)

\section{CONSIDERAÇÕES FINAIS}

Há uma intencionalidade na (re) construção e utilização de variados mecanismos e espaços a exemplo das festas, das formas associativas e dos modos de vida, pensados para indicar processos 
indenitários e consequente territorialidade quilombola. Também há conflitos de memórias no processo de construção da identidade e isto reflete nos modos de territórialização e apropriações diversas.

Percebe-se o quanto o quilombo Matupiri apresenta diálogos com outros contextos (globais, nacionais e regionais), assim como com agentes "externos" que auxiliam na politização da sua Identidade. Um dos elementos iniciais dos processos de constituição da Identificação quilombola encontra-se na construção de uma "memória do cativeiro. Memória essa materializada nas inúmeras festas ali realizadas cada vez mais de modo sistemático.

Compreender como o Matupiri se disse e se auto identifica quilombola passa antes de tudo por identificar e compreender os inúmeros processos e formas de conhecimentos por eles acionados e utilizados. 


\section{REFERÊNCIAS}

ALMEIDA, Alfredo Wagner Berno de. Terra de quilombo, terras indígenas, "babaçuais livre", "castanhais do povo", faixinais e fundos de pasto: terras tradicionalmente ocupadas. - 2." ed, Manaus: pgsca-ufam, 2008.

Almeida, Alfredo Wagner Berno de. Quilombolas e novas etnias / Alfredo Wagner Berno de Almeida. - Manaus: UEA Edições, 2011.

BURKE, Peter. Hibridismo cultural. São Leopoldo: Editora UNISSINOS, 2003.

BRANDÃO, André; da Dalt, Salete; Goveia, Victor Hugo. Comunidades quilombolas no Brasil: características socioeconômicas, processos de etnigênese e políticas sociais. Niterói.:Euf., 2010.

FUNES, Eurípedes. Mocambos do Trombetas: memória e Etnicidade (séculos XIX e XX).In: Gomes, Flávio \& Del Priore, Mary (Orgs). Os Senhores dos rios - Amazônia, Margens e Histórias. Elsevier Ed. São Paulo, 2003.

GUERREIRO, Ana R. P. \& Rocha, João. M. Cultura e Identidade quilombola no Matupiri . Relatório de Pesquisa. Programa de Apoio à Iniciação Científica-PAIC/UEA/FAPEAM (2013-2014).

HALL, Stuart. A Identidade cultural na pós-modernidade. 9.ed. RJ:DP\&A, 2004.

MATTOS, Hebe. "Remanescentes das comunidades dos quilombos": memória do cativeiro e políticas de reparação no Brasil. Revista USP, São Paulo, n.68, p.104-111. Dezembro/fevereiro 2005-2006

MEIHY, José Carlos Sabe Bom. Manual de História Oral. 5. ed. São Paulo: Vértice, 2005.

MEIHY, José Carlos Sebe Bom \& HOLANDA, Fabiola. História Oral: como fazer, como pensar. São Paulo, Contexto,2011.

NOGUEIRA, Wilson. O mercado faz a Festa na Floresta. In: Somalu: Revista de Estudos Amazônicos do Programa de Pós-graduação em Sociedade e Cultura na Amazônia da Universidade Federal do Amazonas. Ano 1, n. 1 (2000).

O'DWYER, Eliane Cantarino (Org.). Quilombos. Identidade étnica e territorialidade. Rio de Janeiro: FGV. 2002.

ORTIZ, Renato. Cultura Brasileira e Identidade Nacional. São Paulo: Brasiliense, 2006.

Pessavento, Sandra Jatahy. História \& História Cultural. 3. Ed.; 1 reimp. - Belo horizonte: Autentica Editora, 2014. 